\title{
3D Numerical Modeling of Flow in Sedimentation Basin
}

\author{
Dhemi Harlan ${ }^{1,}$, Dantje K. Natakusumah ${ }^{1}$, Mohammad Bagus Adityawan ${ }^{1}$, Hernawan Mahfudz ${ }^{1}$, and Fitra Adinata ${ }^{2}$ \\ ${ }^{1}$ Water Resources Engineering Research, Institut Teknologi Bandung, Jl. Ganesa No. 10 Bandung, Indonesia \\ ${ }^{2}$ PT Sapta Adhi Pratama Consultant Bandung, Indonesia
}

\begin{abstract}
Normal operation sedimentation basin flushing systems require large volumes of water, typically up ten times of the deposited sediment volume for efficient flushing. A complete sediment removal, can only be realized by combination of mechanical removal with drawdown flushing. This operation reaches much longer operation time resulting in water loss and reducing power and energy production of Mini Hydro Power Plant (MHPP). The objective of this study is to improve the flushing system of sedimentation basin based on a numerical approach. Fluid motion is described with non-linear, transient, second-order differential equations. A numerical solution of these equations involves approximating the various terms with algebraic expressions. The resulting equations are then solved to yield an approximate solution to the original problem. The simulation result shows that the $3 \mathrm{D}$ numerical modeling of flow in sedimentation basin gives the reasonable result to predict the suspended load movement in the flow.
\end{abstract}

\section{Introduction}

Mini Hydro Power Plant has installed an 6,7 MW mini hydro power plant located in Pasir Melayu Village, Sialu Kahean Sub District, Simalungun District, North Sumatera. Unfortunately, it has experienced severe problems with silt in the head-works and subsequent damage to equipment. The problem caused very serious impact because that sediment coarser than $0.20 \mathrm{~mm}$ in size was harmful for turbine blades and excess of the carrying capacity of the canal. As result, the excess sediment load has to be eliminated from sedimentation basin as part of regularly scheduled maintenance activities and it has increased maintenance load and cost.

Normal operation sedimentation basin flushing systems require large volumes of water, typically up ten times of the deposited sediment volume for efficient flushing. In sedimentation basin, however, a complete sediment removal, can only be realized by combination of mechanical removal with drawdown flushing. This operation reaches much longer operation time resulting in water loss and reducing power and energy production of mini hydro power plant. Therefore, it is important to have an effective and efficient sedimentation basin.

There are various design codes for a sedimentation basin. These codes are mostly based on empirical approaches. A past study has shown that they may not provide accurate results, requiring a site specific modification [1]. However, a site specific design can be assessed using a laboratory experiment or a numerical model. The effectiveness of a retention basin was evaluated using a 1D model with good accuracy [2]. However, a 1D model may not be suitable for assessing the hydraulic condition in a sedimentation basin with a submerged hydraulic structure, e.g. a flushing gate, as in the case of this study. In this case, a 3D model is more accurate. A study was conducted using a 3D numerical model to evaluate the efficiency of a sedimentation basin with various configurations [3]. The results provide a more detail on the effectiveness of a sedimentation basin.

The objective of the study is to evaluate the flow in a sedimentation basin by using a 3D model in order to assess the effectiveness of the basin, and to improve the flushing system of a sedimentation basin system based on a numerical approach.

\section{Technical Data of Karai-7 Mini Hydro Power Plant}

The technical data of Mini Hydro Power Plant are obtained based on the design report [4]. The analysis in this study was focused on the sedimentation basin of Mini Hydro Power Plant in Karai-7 location. The inflow and outflow discharges of the sedimentation basin for short period were measured by the consultant [5], and some sediment samples both suspended and bed loads. We use these data in our computation and analysis. This study focuses on flow modeling for obtaining the flow characteristic in sedimentation basin. However, in this section, we explain them briefly such as sedimentation basin, inflow and outflow discharge, and sediment grain size.

\footnotetext{
* Corresponding author: dhemi@si.itb.ac.id
} 


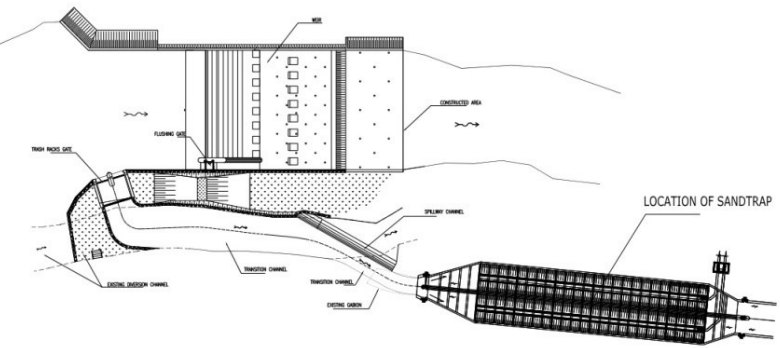

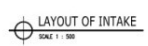

Fig. 1. Layout of Sedimentation Basin Source: Design Report, PT BHE 2014

\subsection{Sedimentation Basin}

Sedimentation basin as one of mini hydro infrastructure is needed to overcome sedimentation problem in water way channel. It is a pond constructed for the purpose of removing entrained solids by sedimentation [6]. Sedimentation along water way channel can reduce channel capacity that affecting the productivity of electricity. The design of sedimentation basin based on the Design Report [4] as Figure 2 following below.

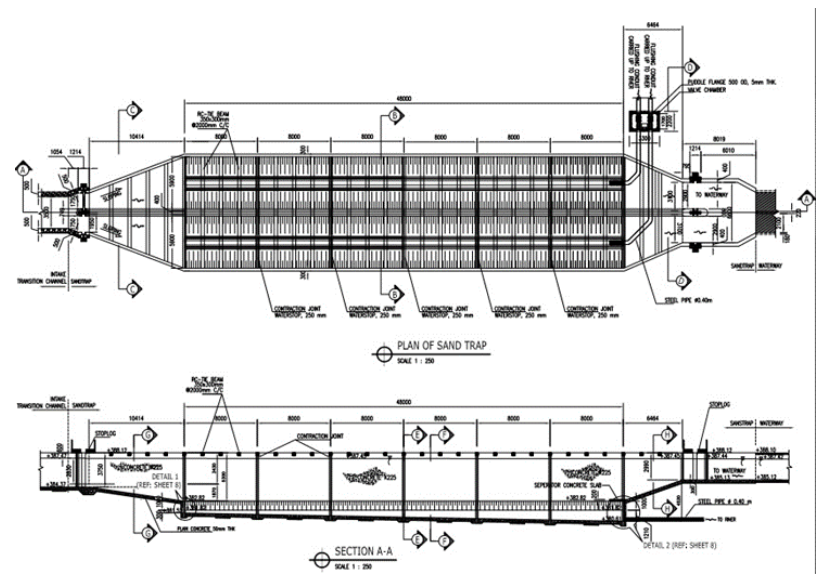

Fig. 2. Sedimentation basin of MHPP Source: Design Report, PT BHE 2014

\subsection{Inflow and Outflow Discharges}

The inflow discharge and outflow discharge are used based on consultant report [5]. The average inflow discharge to sedimentation basin has the value of 13,5 $\mathrm{m} 3 / \mathrm{s}$ and the value of $8 \mathrm{~m} 3 / \mathrm{s}$ for the average outflow. The reducing of discharge between inflow and outflow is about $40 \%$. This could be caused by the sedimentation problem in the basin. This problem will affect the productivity of electricity. Based on installed capacity, the Karai-7 mini hydro just produces around $4 \mathrm{MW}$ of electricity.

\subsection{Sediment Grain Size}

Removal of suspended particles by sedimentation depends upon the size and specific gravity of those particles. Suspended solids retained on a filter may remain in suspension if their specific gravity is similar to water while very dense particles passing through the filter may settle. Solids that can settle are measured as the visible volume accumulated at the bottom of basin [5]. Periodically this sediment is flushed every 2 days because the basin is full. All of the sediments are sand or sandy. The distribution of sand is more than $90 \%$. Mostly has diameter between 0.1 and $1 \mathrm{~mm}(70 \%-90 \%)$, Seven (7) \% or less has diameter more than $2 \mathrm{~mm}$. D50 is around $0.5 \mathrm{~mm}$, less than $0.2 \mathrm{~mm}$ allowed passing the turbine.

\section{Mathematical Formulation}

The differential equations to be solved are written in terms of Cartesian coordinates $(x, y, z)$. For cylindrical coordinates $(r, \theta, z)$, the $\mathrm{x}$-coordinate is interpreted as the radial direction, the $y$-coordinate is transformed to the azimuthal coordinate, $\theta$, and $\mathrm{z}$ is the axial coordinate. For cylindrical geometry, additional terms must be added to the Cartesian equations of motion. These terms are included with a coefficient $\xi$, such that $\xi=0$ corresponds to Cartesian geometry, while $\zeta=1$ corresponds to cylindrical geometry. All equations are formulated with area and volume porosity functions. This formulation is called Fractional Area-Volume Obstacle Representation (FAVOR) Method, used to model complex geometric regions [7].

\subsection{Governing Equation}

The flow can be modeled by using continuity equation, momentum equation, and the volume of fluid equation in Cartesian coordinate. These equations are presented in equation 1 to 3 below.

$$
\begin{aligned}
& \frac{V_{F}}{\rho c^{2}} \frac{\partial p}{\partial t}+\frac{\partial}{\partial x}\left(u A_{x}\right)+R \frac{\partial}{\partial y}\left(u A_{y}\right)+\frac{\partial}{\partial z}\left(u A_{z}\right)+\xi \frac{v_{\rho} A_{x}}{x}=\frac{R_{S O R}}{\rho} . \\
& \frac{\partial u}{\partial t}+\frac{1}{V_{F}}\left\{u A_{x} \frac{\partial u}{\partial x}+v A_{y} R \frac{\partial u}{\partial y}+w A_{z} \frac{\partial u}{\partial z}\right\}+\xi \frac{A_{y} v^{2}}{x V_{F}} \\
& =-\frac{1}{\rho} \frac{\partial p}{\partial x}+G_{x}+f_{x}-b_{x}-\frac{R_{S O R}}{\rho V_{F}}\left(u-u_{w}-\delta u_{s}\right) \\
& \frac{\partial v}{\partial t}+\frac{1}{V_{F}}\left\{u A_{x} \frac{\partial v}{\partial x}+v A_{y} R \frac{\partial v}{\partial y}+w A_{z} \frac{\partial v}{\partial z}\right\}+\xi \frac{A_{y} u v}{x V_{F}} \\
& =-\frac{1}{\rho}\left(R \frac{\partial p}{\partial y}\right)+G_{y}+f_{y}-b_{y}-\frac{R_{S O R}}{\rho V_{F}}\left(v-v_{w}-\delta v_{s}\right) \\
& \frac{\partial w}{\partial t}+\frac{1}{V_{F}}\left\{u A_{x} \frac{\partial w}{\partial x}+v A_{y} R \frac{\partial w}{\partial y}+w A_{z} \frac{\partial w}{\partial z}\right\} \\
& =-\frac{1}{\rho} \frac{\partial p}{\partial z}+G_{z}+f_{z}-b_{z}-\frac{R_{S O R}}{\rho V_{F}}\left(w-w_{w}-\delta w_{S}\right) \\
& \frac{\partial F}{\partial t}+\frac{1}{V_{F}}\left[\frac{\partial}{\partial x}\left(F A_{x} u\right)+R \frac{\partial}{\partial y}\left(F A_{y} v\right)+\frac{\partial}{\partial z}\left(F A_{z} w\right)+\frac{\xi F A_{x} u}{x}\right]=F_{S O R}
\end{aligned}
$$

Where $V_{F}$ is the fractional volume open to flow, $\rho$ is the fluid density, $\mathrm{c}^{2}$ is the square of the sound speed, and $\mathrm{R}_{\mathrm{SOR}}$ is a mass source. The velocity components $(\mathrm{u}, \mathrm{v}, \mathrm{w})$ are in the coordinate directions $(\mathrm{x}, \mathrm{y}, \mathrm{z})$ or $\left(\mathrm{r}, \mathrm{R}_{\mathrm{SOR}}, \mathrm{z}\right)$. $A_{x}$ is the fractional area open to flow in the $\mathrm{x}$-direction, and $A_{x}, A_{y}, A_{z}$ are similar area fractions for flow in the 
$\mathrm{y}$ and $\mathrm{z}$ directions, respectively. The coefficient $\mathrm{R}$ depends on the choice of coordinate system in the following way. When cylindrical coordinates are used, derivatives must be converted to azimuth derivatives.

In these equations, $\left(\mathrm{G}_{\mathrm{x}}, \mathrm{G}_{\mathrm{y}}, \mathrm{G}_{\mathrm{z}}\right)$ are body accelerations, $\left(f_{x}, f_{y}, f_{z}\right)$ are viscous accelerations, and $\left(b_{\mathrm{x}}, \mathrm{b}_{\mathrm{y}}, \mathrm{b}_{\mathrm{z}}\right)$ are flow losses in porous media or across porous baffle plates, and the final terms account for the injection of mass at a source represented by a geometry component.

The term $U_{w}=\left(u_{w}, v_{w}, w_{w}\right)$ in Equation (2) is the velocity of the source component, which will generally be non-zero for a mass source at a General Moving Objects Model. Meanwhile the term $U_{\mathrm{s}}=\left(\mathrm{u}_{\mathrm{s}}, \mathrm{v}_{\mathrm{s}}, \mathrm{w}_{\mathrm{s}}\right)$ is the velocity of the fluid at the surface of the source relative to the source itself.

\subsection{Numerical Model}

\subsubsection{Model Geometry}

Geometry is constructed by assembling solid geometric objects to define the flow region for a simulation, as shown in Figure 3.
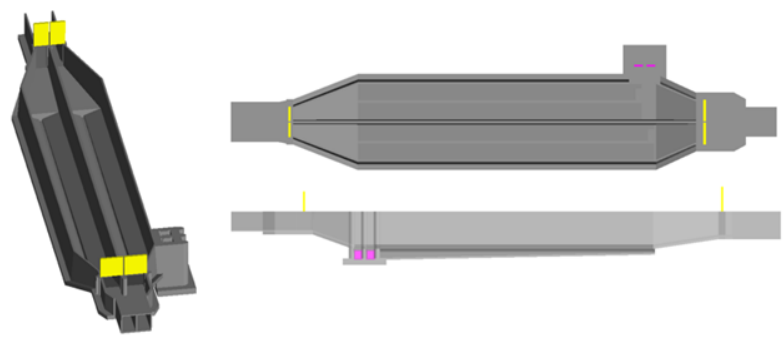

Fig. 3. 3D model of Karai-7 sedimentation basin

\subsubsection{Model Mesh Block}

The most basic mesh in FLOW-3D is a single-block mesh, i.e. only one mesh block is used to define the domain. The default settings for a mesh block will create a uniform mesh, which is a mesh with a uniform cell size in all directions for this model the cell size uniformly by $0.15 \mathrm{~m}$ each. These may be created by supplying only a cell size, a total number of cells, or a specific number of cells in each coordinate direction as shown in Figure 4. It is also possible to define multiple mesh blocks (multiblock gridding) to create more efficient meshes when modeling complex flow domains. The additional mesh blocks may be defined to be fully within another mesh block (including aligned with the containing block boundaries; this is called a nested block), they may adjoin at a boundary of another mesh block (called a linked block), or they may partially overlap.

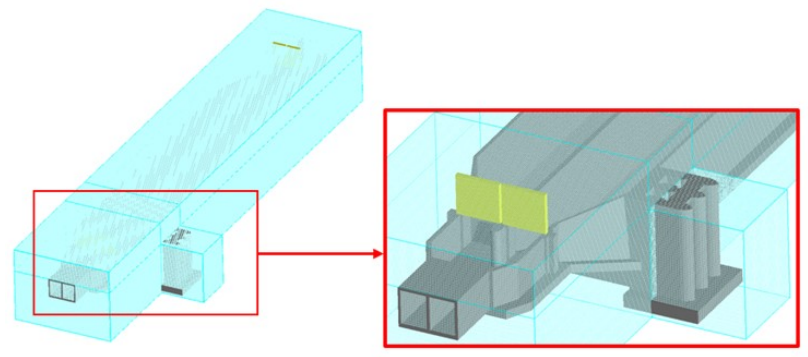

Fig. 4. Model block-grid

\subsubsection{Boundary Condition}

The boundary conditions associated with Geometry are handled by the choice of component type or via other component-specific properties that are associated with a particular physical model/equation (described in Model Reference). However, boundary conditions on the faces of each mesh block also need to be defined as shown in Figure 6 and Table 1 below.

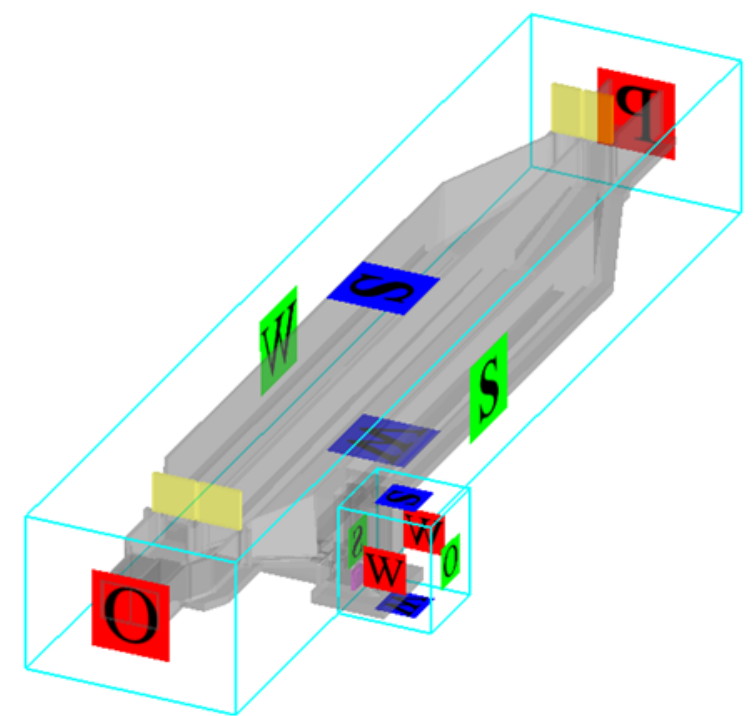

Fig. 5. Boundary conditions in model Karai-7 Sedimentation Basin

Table 1. Boundary conditions in the model

\begin{tabular}{|c|c|c|c|c|c|c|c|c|}
\hline \multirow{2}{*}{ No Block } & \multirow{2}{*}{ Block Name } & \multirow{2}{*}{ Cell Size } & \multicolumn{6}{|c|}{ Boundary Conditions } \\
\hline & & & $\mathrm{X}$ min & $\mathrm{X}_{\max }$ & $Y_{\min }$ & $\gamma_{\max }$ & $2 \min$ & $Z \max$ \\
\hline Mesh Block 1 & Block 1 & $0.5 \mathrm{~m}$ & $\mathbf{p}$ & $\mathbf{0}$ & $\mathbf{w}$ & $\mathbf{s}$ & $w$ & $\mathbf{s}$ \\
\hline Mesh Block2 & Block 2 & $0.5 \mathrm{~m}$ & $\mathbf{w}$ & $w$ & $\mathbf{s}$ & $\mathbf{0}$ & $\mathbf{w}$ & $\mathbf{s}$ \\
\hline
\end{tabular}

\subsubsection{Initial Condition}

Initial conditions define the starting conditions in the simulation. As mentioned in Mesh Boundary Conditions, the initial state of the solution for transient fluid flow problems must be known in order to find a solution and, in a manner similar to what is done with boundary conditions, the initial conditions are assumed, approximating the true state at time $t=0$. The accuracy of the initial conditions is somewhat less important than 
that of the boundary conditions because their effect is reduced as time progresses. Because of this effect, it is common to define the initial geometry of the fluid with reasonable accuracy but to assume that the pressure and velocity fields are uniform. This typically produces good results with a relatively short time where the solution is affected by physical initial conditions.

Fluid regions are used to define areas of fluid in a manner similar to how sub components are defined. As such, they may be defined using limiters, coefficients for a quadratic function. In the case where the quadratic function is used the use function coefficients for box provides control over how the input coefficients (set in the Coefficients branch) are interpreted. The other options are used to define distributions of different quantities (density, temperature, velocity, etc.).

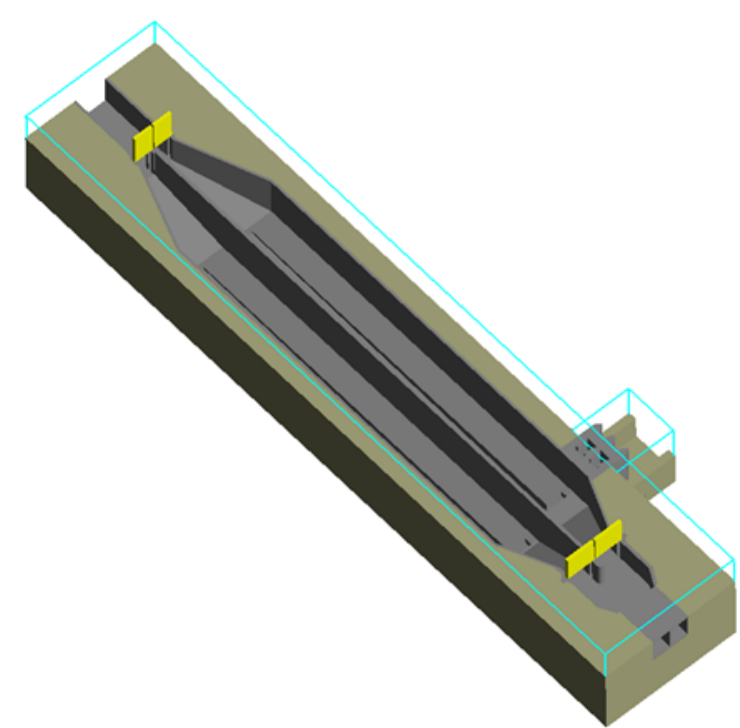

Fig. 6. Initial conditions $\mathrm{t}=0$ in model Karai-7 Sedimentation Basin shows the model has no fluid

\section{Result and Discussion}

Figures 7 to 9 show the vertical velocity distribution along the left and right chambers at 60, 120 and 180 seconds, respectively. These results are important to assess whether the sediment basin can effectively trap the sediment. In general, the vertical velocity distribution in both chambers shows similar behavior.

The velocity distribution on the surface of the basin is given in Figures 7(a), 8(a)and 9(a), for 60, 120, and 180 seconds respectively. The sedimentation basin is divided into two chambers, left and right. The flushing gate is located in the left chamber (looking from downstream). In general, the flow distribution in the right and left chambers are similar. However, the flow magnitude tends to be higher in the left chamber. This is caused by the release square hole location of right chamber from center line of basin not similar position compared to the left one.

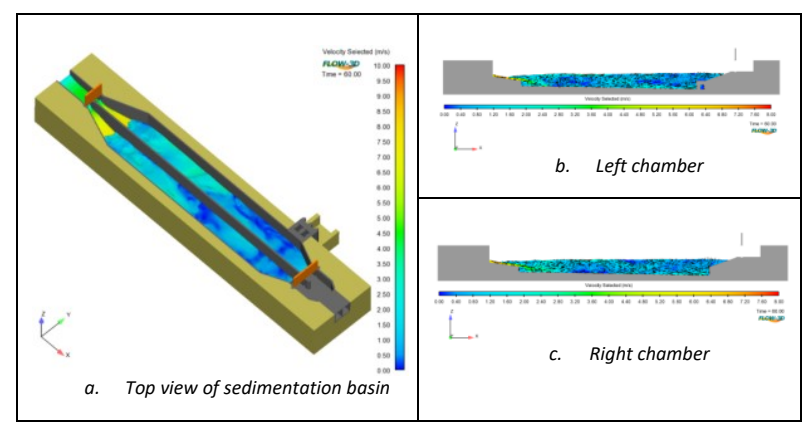

Fig. 7. Modeling result of velocity magnitude for $\mathrm{t}=60$ 'sec

The flow velocity was reduced significantly after entering the basin. Figure 7 shows the horizontal velocity distribution on surface at 60 seconds after the gate was opened. The flow velocity at the first half of the basin is approximately $2 \mathrm{~m} / \mathrm{s}$, which is reduced to $1 \mathrm{~m} / \mathrm{s}$ at the last half.

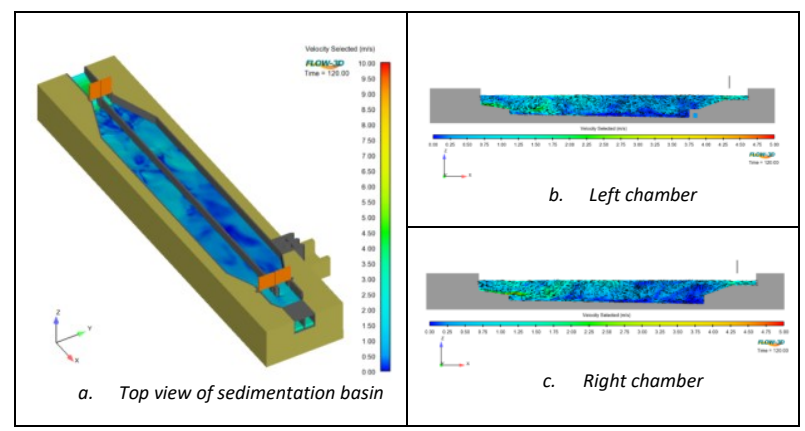

Fig. 8. Modeling result of velocity magnitude for $\mathrm{t}=120$ 'sec

Figure 8 shows the model result at 120 seconds, the flow velocity is much calmer along the basin. It is shown here that the surface velocity is less than $1 \mathrm{~m} / \mathrm{s}$, and it is still higher than $0.3 \mathrm{~m} / \mathrm{s}$. It is expected that the velocity magnitude should be less than $0.3 \mathrm{~m} / \mathrm{s}$ to allow sediment deposition in the basin or to trap the minimum size of 0.2 $\mathrm{mm}$ sediment. The simulation reaches a stable condition after 180 seconds as shown in Figure 9.

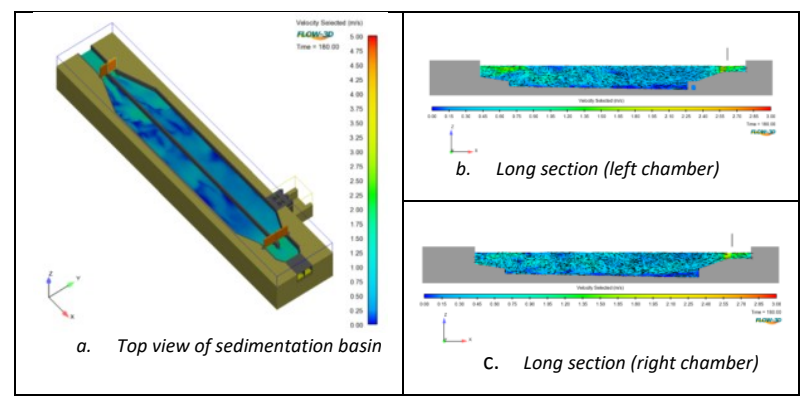

Fig. 9. Modeling result of velocity magnitude for $\mathrm{t}=180$ 'sec

Figure 10 shows six observation locations for the left and right chambers in Cartesian coordinate that every location consists of three depths: top, middle, and bottom of water surface. Hence, observation points consist of nine point probes for every chamber. 


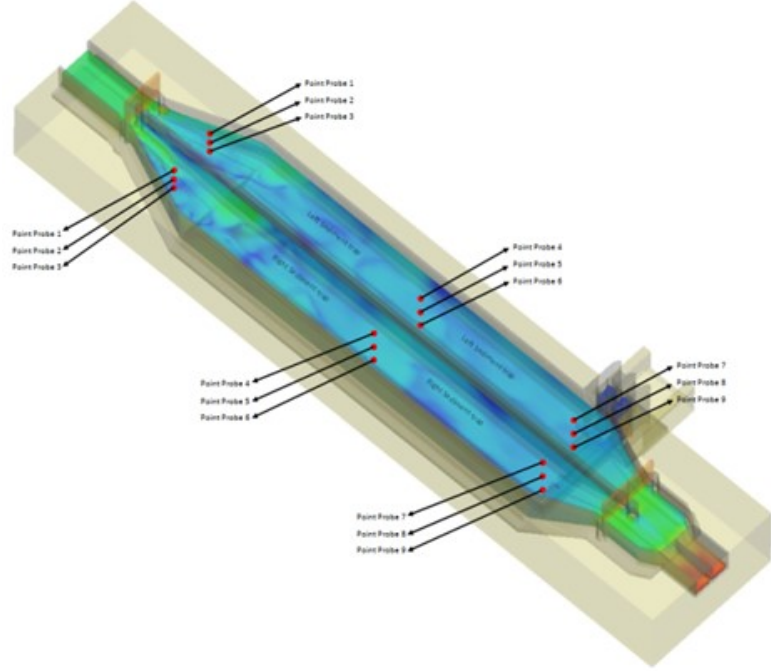

Fig. 10. Left and right sediment chambers Point probes of model observation

\begin{tabular}{lccclrrc}
\multicolumn{4}{c}{ Left Chamber } & \multicolumn{5}{c}{ Right Chamber } \\
Probe Name & \multicolumn{1}{c}{ X } & $Y$ & $Z$ & Probe Name & $X$ & $Y$ & $Z$ \\
PROBE 1 & 15 & 10.95 & 6.675 & PROBE 1 & 15 & 6.5 & 6.675 \\
PROBE 2 & 15 & 10.95 & 5.675 & PROBE 2 & 15 & 6.5 & 5.675 \\
PROBE 3 & 15 & 10.95 & 4.875 & PROBE 3 & 15 & 6.5 & 4.875 \\
PROBE 4 & 43 & 11.95 & 6.675 & PROBE 4 & 43 & 5.45 & 6.675 \\
PROBE 5 & 43 & 11.95 & 4.875 & PROBE 5 & 43 & 5.45 & 4.875 \\
PROBE 6 & 43 & 11.95 & 3.275 & PROBE 6 & 43 & 5.45 & 3.275 \\
PROBE 7 & 64.5 & 11.95 & 6.675 & PROBE 7 & 66.5 & 5.45 & 6.675 \\
PROBE 8 & 64.5 & 11.95 & 4.675 & PROBE 8 & 66.5 & 5.45 & 4.675 \\
PROBE 9 & 64.5 & 11.95 & 2.175 & PROBE 9 & 66.5 & 5.45 & 2.175
\end{tabular}

Figures 11 to 13 show the flow velocity at 60 seconds in the left and right chambers, accordingly. The flow velocity near the bed is high along the basin in both chambers, approximately $2 \mathrm{~m} / \mathrm{s}$, although the velocity near the surface is less than $1 \mathrm{~m} / \mathrm{s}$. The near bed velocity is not low enough to trap the sediment.
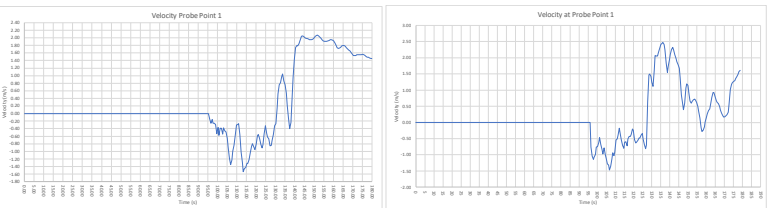

Fig. 11. Velocity at point probe 1 (left and right sediment-trap)
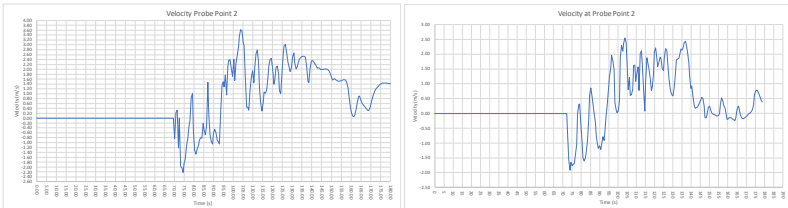

Fig. 12. Velocity at point probe 2 (left and right sediment-trap)
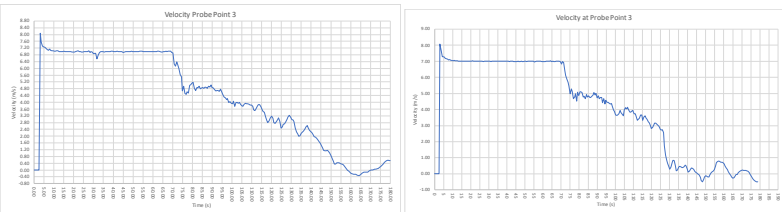

Fig. 13. Velocity at point probe 3 (left and right sediment-trap)
Figure 14 to 16 show the flow velocity at 120 seconds in the left and right chambers. The near bed velocity is significantly low, less than $0.25 \mathrm{~m} / \mathrm{s}$, which is low enough to deposit $0.2 \mathrm{~mm}$ sediment. However, the vertical velocity distribution at the first half of the basin is higher than $1 \mathrm{~m} / \mathrm{s}$.
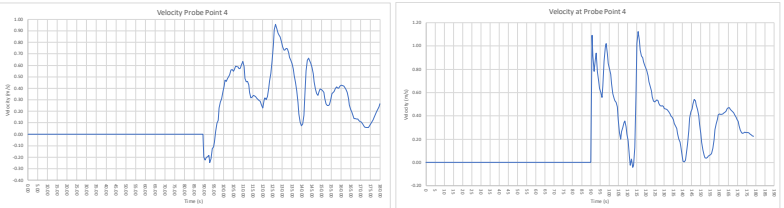

Fig. 14. Velocity at point probe 4 (left and right sediment-trap)
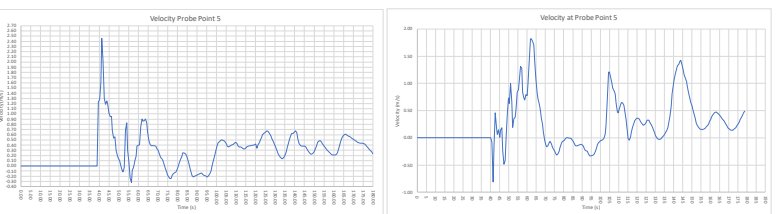

Fig. 15. Velocity at point probe 5 (left and right sediment-trap)

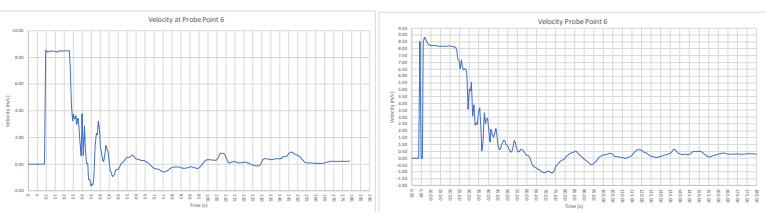

Fig. 16. Velocity at point probe 6 (left and right sediment-trap)

The stable condition is given in Figures 17 to 19 , at 180 seconds for the left and right chambers. Both chambers are equally effective for trapping the sediment. In general, the velocity magnitude in both chambers is lower than $0.3 \mathrm{~m} / \mathrm{s}$. This magnitude is sufficiently low to deposit $0.2 \mathrm{~mm}$ sediment.
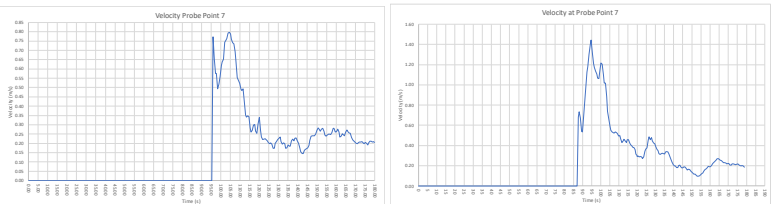

Fig. 17. Velocity at point probe 7 (left and right sediment-trap)
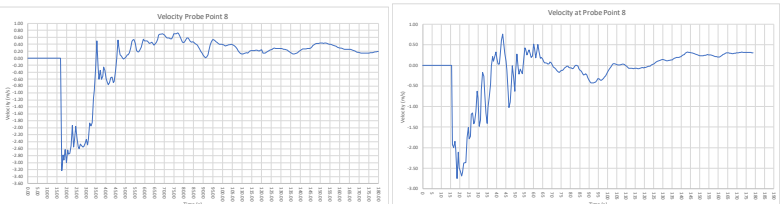

Fig. 18. Velocity at point probe 8 (left and right sediment-trap)
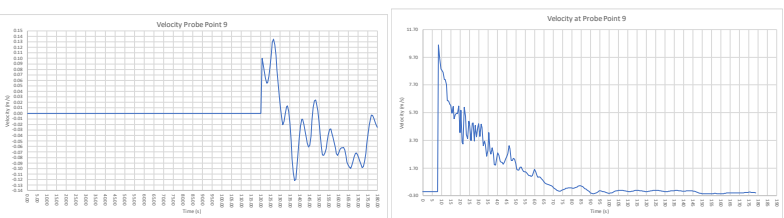

Fig. 19. Velocity at point probe 9 (left and right sediment-trap) 


\section{Conclusion}

The sedimentation basin is expected to trap sediment with the diameter of $0.2 \mathrm{~mm}$. A velocity magnitude of approximately $0.3 \mathrm{~m} / \mathrm{s}$ is expected to allow this sediment to deposit. It was found from the vertical velocity distribution that the velocity magnitude in the basin is less than $0.3 \mathrm{~m} / \mathrm{s}$. Therefore, the sedimentation basin is effective for less than $0.2 \mathrm{~mm}$ sediment. This shows that 3D numerical modeling of flow in sedimentation basin gives the reasonable result to predict the suspended load movement in the flow. It is recommended to conduct a coupled hydraulic and sediment transport simulation to assess in more detail the effectiveness of the sedimentation basin. The simulation may also provide an in depth understanding of the sedimentation rate in the basin.

This work is supported by the Faculty of Civil and Environmental Engineering, ITB through The Program of Research, Community Service, and Innovation for Research Division ITB (P3MI ITB), year 2017.

\section{References}

1. S.E. Lewis, Z.T. Bainbridge, P.M. Kuhnert, B.S. Sherman, B. Henderson, C. Dougall, M. Cooper \& J.E. Brodie. Calculating Sediment Trapping Efficiencies For Reservoirs In Tropical Settings : A Case Study From The Burdekin Falls Dam, NE Australia. Water Resources Research (49), pp. 1017-1029, 2013. doi:10.1002/wrcr.20117,

2. H. Toniolo \& G. Parker. 1D Numerical Modeling Of Reservoir Sedimentation, Proceedings of IAHR Symposium on River, Coastal and Estuarine Morphodynamics, pp.457-468, 2003.

3. A. Taylor, G. Macky \& A. Gasc. Sedimentation pond Performance from Three-Dimensional Modelling. Asia Pacific Stormwater Conference, 2015.

4. PT BHE. Design Drawing of Karai-7 Mini Hydro Poer Plant. PT Global Karai, 2014.

5. Lapi ITB. Watershed Level Risk Assessment for Karai-7 Mini Hydro Power Plant Development. MCA Indonesia, 2017. (Book)

6. Goldman, J. Steven, Jackson, Katharine \& Bursztynsky, A. Taras. Erosion \& Sediment Control Handbook. McGraw-Hill. ISBN0-07023655-0. pp. 8.2, 8.12., 1986. (Book)

7. Flow Science Team. Flow-3D User manual. Flow Science, Inc., 2008. 